\title{
Coalition for photonics and optics
}

\section{Robert Breault}

Robert P. Breault, "Coalition for photonics and optics," Proc. SPIE 4588, Seventh International Conference on Education and Training in Optics and Photonics, (28 May 2002); doi: 10.1117/12.468730

SPIE Event: Education and Training in Optics and Photonics 2001, 2001, Singapore, Singapore 
Invited Paper

\title{
Coalition for Photonics and Optics
}

\author{
Robert P. Breault \\ Breault Research Organization, Inc. \\ 6400 East Grant Road, Suite 350 \\ Tucson, AZ 85715
}

\begin{abstract}
The Coalition for Optics and Photonics (CPO) happened for all the best of reasons, while born out of a somewhat tumultuous past that could not have predicted it. First, there were optical societies. Born from each other, or because of each other, they had their own agendas. Each felt strongly that they had the one and only right path. There was little cooperation and even, from time to time, some non-constructive competition among the professional societies and trade associations. The optical industry was still in its infancy stage for the most part.

It was probably due to the combination of intelligent people from all societies, and the rapid growth of the industry and their conferences that made some coordination necessary. What started as high-level discussions, complete with some staff, led to a better understanding and cooperation between the societies and preceded the formation of CPO.
\end{abstract}

\section{INTRODUCTION}

In the late 1980's and into the early 90's there was a conference called OptCon. Its Steering Conference Committee first brought together leadership from OSA, SPIE, LEOMA, IEEE/LEOS, and LIA. The societies also brought staff and volunteers to the same table several times a year for informal discussion of non-OptCon issues. Generally constructive (although sometimes "frank") discussions at OptCon Steering led to better relationships among the societies and associations. OptCon was discontinued around 1993 for lack of exhibitor support. There was subsequently no forum for intra-society discussions.

In the mid 90 's, a fairly large group of optical scientist and interested parties came together to study the breadth, depth, and future of the optics and photonics industry. This group became know as the Committee for Optics and Photonics (COSE), authors of the now famous COSE report. In 1996, at Art Guenther's request for the last meeting of the committee, Art suggested that they should hear from other leading organization in the industry for any further input before finalizing the study. That brought together SPIE, IEEE, LEOS, OSA, and LEOMA.

\section{MARKERS ALONG THE WAY}

The Coalition for Optics (later renamed CPO) was formed in 1996, primarily under the leadership of Jim Pearson, Duncan Moore, and David Hennage. Its initial mission was to:

Establish "optics" as a discipline

Publicize the COSE report

Explore additional activities to benefit the community

In 1998, under Randy Heyler's leadership, CPO addressed four areas to benefit the community:

Education

Promoting optics and photonics as career choices

Public policy

Standards

Industry census (a compilation of the U.S. companies that depend on optics) 
CPO has eleven member organizations, represents a total of 30,500 optical scientists, engineers and technicians, and 513 U.S. opto-electronics companies. CPO continues to provide a viable, constructive forum for the societies and associations to coordinate their activities.

- Some current CPO activities:

- Coordinate input from various societies and associations to the $\mathrm{CPO}$ web site.

- Continue to build industry census

- Support increasing the issuance of H1B's work visas

- Support the inclusion of more NAICS (formerly SIC) codes for optics and photonics

- Support OEOSC in creation of international optics standards

- Pool funding from societies to reprint COSE Executive Summary

- Coordinate LEOMA, OIDA, and APOMA in revising the

- $\quad$ Pool funding from societies to update the COSE Executive Summary

- Coordinate LEOMA, OIDA, and APOMA in revising the North American Industrial Classification System (NAICS).

- $\quad$ Hold periodic federal funding forums

- Have its members support Congressional Visit Day to inform congressional members of the economic impact of optics and photonics on the economy and the shortages in the current and future workforce.

Probably the two primary initiatives of CPO were the dissemination of the COSE report, and recognition of "optics" as a curriculum and a career choice. While there may be lingering undone tasks from those projects, the single issue overarching the entire community is a looming manpower shortage. The Coalition for Photonics and Optics is now a cooperative activity among societies and associations participating in the international photonics and optics community designed to unite the community by providing a forum for discussion on common interests. The CPO also provides a mechanism for coordinated community action on matters that will further the common interests of the global community. At CPO meetings, members present their society or organization's current activities, and discuss where cooperation might help. Below is a synopsis of some of the topics that have been discussed, to give a feel for the breadth of the discussions.

\section{CPO MANPOWER SEMINAR SO MANY JOBS...SO FEW PEOPLE}

Members of the Coalition for Photonics and Optics met in Washington on June 19, 2000 with senior public policy makers and human resource managers in a productive examination of the worker shortage facing the optics industry. Representatives from academia, leading photonics companies, and optics-related associations filled a theater in the Hyatt Regency Washington on Capitol Hill to hear the latest sobering statistics. Among the bad news: waning enthusiasm in science and math among grade-school students; a steady decline in the number of science and engineering degrees being awarded by U.S. institutions of higher learning; and fierce international competition for the relatively small pool of qualified optics technicians and engineers.

Participants left with a greater understanding of the scope of the crisis and valuable information about both current and future manpower needs of the optics community. Fundamentally, the study said that the world is short of optical engineers and optical technicians, and the projection is that we will be four times further behind in five years. There are several factors that have created this challenge. Not all of them are bad. First and foremost is that optics and photonics product development are growing rapidly, which is different than the second point. The technology in the optics industry is one of the all-time fastest growing among other industries. The optics industry is maturing faster, reaching its period of mass commercialization faster than past "industrial revolutions". Thirdly, the universities have not had the time to develop the academic programs to feed students into the workforce. And furthermore young children haven't had the time period to get interested in optics. Career paths in optics are yet to be heavily promoted. Hence the feeder stream of future optics employees is yet to develop. The demand now for optically trained people far outstrips the supply capability. No one can be blamed for not seeing the future when there has never been a comparable situation. 
The problem is further complicated by two other factors. The first one, which has been known for some time, is the ever-decreasing number of students going into the hard sciences and engineering. Furthermore the world is finally starting to realize the impact of some of the changes in demographics in the last ten years. It appears that the world will not burst at it seams from a population explosion. In fact the opposite is true. Many nations will shortly be desperate for workers in just about every field: nurses, teachers, construction workers, general laborers, technical people, etc. Birth rates have been below 2.1 per female for many years; hence many countries are no longer replacing their workforce with an equal number of workers. In the next 15 years, many of the baby boomers are going to leave the workforce; for every ten that leave there will only be one new worker to replace them. For the last six years at Los Alamos, for every 100 nuclear scientists that have departed, only four new recruits have replaced them. If the average experience of a retiree is about 40 years, that means that $40 * 100=4,000$ man-years are being replaced with, at most, 16 man-years. How can you grow under those circumstances? In optics we need to assure that proportionally more students enter into optics careers.

Example: A joint forum by LEOMA and OSA and supported and promoted by other CPO members in June 2000, focused on manpower shortages and potential solutions.

Some of the topics covered at the June conference were:

- Human Resources Panel: "How hard can it be to hire an optical engineer/technician?"

- A PowerPoint presentation for college freshmen and high school seniors

- An intriguing optics demonstration for grade school children

- The role of professional societies in attracting and retaining men \& women in photonics

- NSF programs for promoting science and technology education

- The STEP program for laser-technician training

- "International competitiveness and the shortage of technology workers"

- The Graduate Assistantships in Areas of National Need program

- The semiconductor industry's successful strategies for alleviating manpower shortages

- Funding universities to promote relevantly educated technical talent

- Panel on immigration solutions

More detailed information on the above sessions can be found at the CPO web site, http://www.cpo-optics.org/AboutCPO/. Its web site includes links to educational web sites, lists of current new books on optics, and special magazines or other publications. As workforce is one of its key initiatives, it will often have links to K-12 sites for students and workforce development issues. It maintains links to state optics organizations, international optics and photonics organizations, government agencies, professional societies and trade associations and corporate information centers. The Coalition for Photonics and Optics also held a Federal Funding Forum on February 3, 2000 Washington, D.C.

\section{CPO Executive Committee}

\section{Chair}

Mr. Breck Hitz

Executive Director

LEOMA

123 Kent Rd.

Pacifica, CA 94044

leoma@sfo.com

\author{
Secretary \\ Mr. John Thorner \\ Executive Director \\ OSA \\ 2010 Mass Ave. NW \\ Washington, DC 20036 \\ jthorn@osa.org
}


Co-Chair

Dr. Gordon Day

Chief, Optoelectronics Division

NIST Boulder Labs -- MS 815

325 Broadway

Boulder, CO 80303

gwday@boulder.nist.gov
Secretariat Contact

Eileen Sangmeister

Executive Assistant to the Director

OSA

2010 Mass. Ave. NW

Washington, DC 20036

esangm@osa.org

\title{
CPO Member Organizations
}

\author{
AOIA Arizona Optics Industry Association \\ APOMA American Precision Optics Manufacturers Association \\ CPIA Colorado Photonics Industry Association \\ LEOMA Laser \& Electro-Optics Manufacturers Association \\ LEOS Lasers \& Electro-Optics Society of the IEEE \\ LIA Laser Institute of America \\ OIDA Optoelectronics Industry Development Association \\ OSA Optical Society of America \\ PIANY Photonics Industry Association of New York \\ SPIE - International Society for Optical Engineering \\ USDC United States Display Consortium
}

\section{MEMBER MEETINGS AND ACTIVITIES}

$\mathrm{CPO}$ has a loosely tied organizational structure. It has accomplished many things without the typical rules and regulations. Members have contributed resources, people and money on an as-needed basis, and to the extent of their individual resources. CPO typically meets three times a year, at Photonics West in January, CLEO in May and the OSA annual meeting in October. However, the by-laws do not regulate the place, day, time or frequency. If a member organization's appointed representative to CPO is absent for three consecutive meetings, and in the absence of a proxy, the organization's MEMBER status is changed to OBSERVER status at/during the third missed meeting. To regain MEMBER status the organization must be approved by the entire CPO membership.

\section{Congressional Visits Day Update}

One of the other CPO key activities in the United States supported by CPO is Congressional Visit Day (CVD). Kathy Ream, SPIE's Washington lobbyist, has coordinated the annual Congressional Visit Day (CVD) usually scheduled in May of each year over a two-day period from dawn to dusk. Any organization wishing to participate has been encouraged to do so. Activities usually have included a breakfast briefing, a report from someone in the federal administration, and small-group office visits directly with national legislators and other events. The entire event is designed to show that there is a constituency group interested in science and technology funding. Past experience has showed that an "agenda" must be in place before such visits, and that the CPO visitors know "what they want" (e.g. increased funding for NSF, education, etc.). Therefore, Kathy Ream and her organizers prepare briefing material and the basic, underlying message is the same - academia and industry working together is vital to economy. Messages may be more tailored by the society, a specific industry, or for specific legislators. One of several positive outcomes of CVD is the establishment of relationships with staffers. OSA has hosted a meeting prior to CVD for participating CPO members to discuss a common agenda and distribute materials on the current issues that are under discussion in Washington. Sometimes this has included issues not to be discussed. The details of the agenda and message change from year to year. It has been successful each year and CPO is discussing how it can expand on the mission. One such way would be to have the legislators to "call" for a congressional hearing on optics and photonics. They need to call for it, since the societies cannot "lobby", but they can testify if called to do so. If such an event were to happen, the industry members would be asked to "exhibit" at an event in one or more of the houses. We are trying to create a national visibility. 


\section{Roundtable Discussion}

Each member organization is asked to discuss issues of common interest or concern, as well as information of relevant current projects within their organization. It is a time to call for cooperation, if any is needed, or for spreading the word for some special event. Typical issues covered at the last meeting included:

\section{NMOIA - New Mexico Optics Industry Association}

- Has about 40 companies participating, doing some funding development and economic development

- New Mexico's US Representative, Heather Wilson, has offered to attempt to raise visibility of optics, both locally and nationally. A white paper is needed to define optics as a separate discipline to the US government.

- Work force development issues. The US needs a new curriculum called "optics" to draw attention to discipline, which is now typically scattered in other university departments, it does not get priority funding.

APOMA - American Precision Optical Manufacturers' Association

- A national organization with 100 manufacturing members and 50 supporting members

- Stress development of interest in optics in high schools - careers available in optics

- 2-year schools - need workforce development at all ages to encourage careers in optics

- Establish training programs to upgrade in internal workplace (within companies)

- APOMA supports Optics and Electro-Optics Standards Council (OEOSC)

- Supports optics as a separate discipline

\section{OIDA - Opto-electronics Industry Development Association}

- OIDA represents industry in opto-electronics. They like the consensus of CPO member's use of the industry as optics or photonics.

- Both EE and optics needed. Against optics as a separate discipline - need combination.

- Workforce shortage - emphasis on graduate education. To a lesser degree, interested in high school education. A textbook is being developed for high school/training.

- DARPA centers of excellence would be a means of further developing the optics industry - optical engineering curriculum.

- The optics industry in general has a lack of infrastructure for high-volume, low-cost manufacture. OIDA would support an Advanced Technology Program (ATP) to solve this shortcoming in the industry.

- New initiative on solid-state lighting (inorganic or organic LEDs) to replace all light sources - many benefits on an international scale

\section{LEOMA - Laser and Electro-Optics Manufacturers' Association}

- Trade association of 30 companies for N. American laser manufacturers.

- Manpower shortage, especially acute in Bay Area, is an issue of survival for member companies. This is a worldwide issue.

- Training programs are needed at local colleges and internal training.

- Instructors are the limiting factor - not enough qualified individuals willing to take the job. In many regions, industry is stealing them away for short-term gains.

- Community college training:

- Yuma college - 1 year training program - 2000 was first year

- San Jose City College - Laser techs - boot camp - 2 week program

- Irvine Valley College - new program

- Most members of CPO want optics defined as a profession, in terms of employee government statistics - "optical engineering". They want the government (Bureau of Labor Statistics) to reflect reality. 
SPIE - The International Society for Optical Engineering

- NSF - SPIE \& OSA have applied for a planning grant for $21^{\text {st }}$ century optics education - a comprehensive document for optics education; will plan a series of workshops to create a document and apply for a larger grant to implement a program.

- Optics as a separate discipline - in the short term, inclusion of optics for product lines, new industry will not be considered until 2007.

- Inform industry to use the correct terms in identifying employee classifications (HR). Today, optics is not included in the national survey that goes out to all major employers. Employees with optics as their classification are therefore not recognized as existing in their statistics. Managers need to be trained to count its optics-related scientists as in optics, rather than electronics or system engineers.

- OSA and SPIE have resigned from AAES and are now counting on CPO to meet their policy needs.

- $\mathrm{CPO}$ needs to revise their strategic plan/charter.

CPIA - Colorado Photonics Industry Association

- New catalog issued with a theme of workforce development - Boulder, CO concentration.

- Trying to attract young people into math and sciences, especially in rural areas. Some projects are started in this initiative. They recognize that careers need to be promoted at all educational levels.

- Undergraduate program - some state funding for an optics lab.

AOIA - Arizona Optics Industry Association

- Now has over 200 optics members in its membership and over 150 other supporting members organized as the Arizona Optics Cluster. The Cluster community planed and held a successful international cluster meeting to discuss cluster development and growth process. On Oct 28-31, 2001, over 21 nations participated. Many cross-national meetings were held.

- AOIA expressed that it would be useful for the global optics community to have a list of all short courses (OSA, SPIE, LEOS, etc.) in one place (perhaps on the CPO Web page).

Penn State University

- Grant to establish a center for electro-optics manufacturing excellence and to run technical projects (from DOD).

- Consider workforce development, outreach for K-12 students and educators.

OSA - Optical Society of America

- Discussed joint OSA/SPIE projects.

- Announced that Duncan Moore was serving as OSA Science Advisor. He will be able to serve as spokesman for OSA. With his past experience in Washington, Moore is an excellent choice to serve as the national representative for the optics industry.

- AIP developing TV spots of science/physics interest - OSA contributing to these spots.

- Educators' Day at OSA's Annual meeting is not an effective program (not reaching enough people). Internally, considering program with more impact - training our members how to teach optics. Create program for members "How To Teach Optics" and train large numbers of members and loan them materials to help them teach.

IEEE/LEOS - Lasers and Electro-Optics Society

- LEOS is part of a much larger organization (IEEE). Primary function is journal and conference. Visit www.ileos.org for more information.

- LEOS has funds available for worthy projects.

- Workforce development - assisting folks who are moving into optics from similar disciplines (transfers) with resources such as short course programs, tutorials, etc. 


\section{Reports from observer organizations}

\section{UK Coalition for Photonics and Optics}

- Attracting students into courses is partly a marketing exercise - use the word "photonics" instead of "optics".

- For UK-funding of photonics programs, photonics is a fuzzy term and it is difficult to classify programs correctly.

\section{OEOSC - Optics and Electro-Optics Standards Council}

- Standards - completed a updated specifics for optical glass.

\section{CONCLUSIONS}

$\mathrm{CPO}$ is the only national program where most of the optical and photonics-related societies and regional optics clusters representing the optics industry can and do interface for the good of the optics community. Without any direct means of soliciting from outside its membership organizations, it is somewhat limited it what it can do. Nevertheless, its coordination efforts, for the most part, have been successful. It has found funding necessary to meet it needs and continues to promote the needs of the optics industry. Much more could be done, but usually each attendee is a leader of an organization to which they already volunteer many hundreds of hours. It is through the member's organizations that the goals of $\mathrm{CPO}$ are best executed. 